\title{
CONSIDERAÇÕES SOBRE A POSIÇÃO ESTRATIGRÁFICA E TECTONISMO DEFORMADOR DA FORMAÇÃO ITAQUERI NA PORÇÃO CENTRO-LESTE DO ESTADO DE SÃO PAULO
}

\author{
Claudio RICCOMINI
}

\author{
RESUMO
}

\begin{abstract}
A Formação Itaqueri, na sua área-tipo, compreende depósitos rudáceos de leque aluviais dispostos sobre as serras de Itaqueri, São Pedro, São Carlos e Cuscuzeiro, cuja gênese está relacionada à evolução da Superfície de Aplainamento Japi. Sua idade paleocênica-eocênica é atribuída pela existência de processos de silicificação hidrotermal penecontemporâneos à sedimentação, associados à colocação de corpos de rochas alcalinas, com esta idade, ao longo do Alinhamento do Rio Moji-Guaçu. O tectonismo deformador desta unidade é caracterizado pela presença de estruturas rúpteis, principalmente falhas e juntas, relacionadas com movimentações ao longo dos alinhamentos estruturais do Rio Tietê, São Carlos - Leme e Rio MojiGuaçu. As falhas possuem um eixo de tensão principal máxima, $\sigma 1$, de orientação NW, horizontal, eixo de tensão principal mínima, $\sigma 3$, NE, horizontal, e eixo intermediário, $\sigma 2$, vertical, compatíveis com um binário transcorrente dextral de direção geral WNW a E-W, provavelmente neotectônico.
\end{abstract}

ABSTRACT

The Itaqueri Formation, in its type-area, comprises rudaceous deposits of alluvial fans covering the serras of Itaqueri, São Pedro, São Carlos and Cuscuzeiro, and its origin is related to the evolution of the Japi Planation Surface. A Paleocene-Eocene age is inferred from the age of alkaline rocks emplaced along the Rio Moji-Guaçu Lineament which caused hydrothermal silicification coeval with the sedimentation. Deformation tectonics of this unit is characterized by brittle structures, mainly faults and joints, related to movements along the Rio Tietê, São Carlos - Leme and Rio Moji-Guaçu Lineaments. The stress-field for these faults presents a horizontal NW-oriented $\sigma 1$, a horizontal NE-oriented $\sigma 3$, and a vertical $\sigma 2$, compatible with a WNW to E-W right-lateral strike-slip binary of probable neotectonic (Quaternary) age.

\section{INTRODUÇÃO}

ALMEIDA \& BARBOSA (1953) atribuíram a designação de Formação Itaqueri para os depósitos areno-conglomeráticos que recobrem as serras de Itaqueri, Santana, São Carlos e Cuscuzeiro, situando-a estratigraficamente sob a Formação Marília, com a qual constituiria o Grupo Bauru. Nos trabalhos que se sucederam, a unidade foi por vezes mantida neste grupo (v.g. AB'SÁBER, 1969; HASUI \& SADOWSKI, 1972; SOARES et al., 1980; BRANDT NETO et al., 1981; BARCELOS et al., 1983), a ele correlacionada, mas com possibilidade de ser mais jovem (PONÇANO, 1981), ou ainda referida como cenozóica, pós-Grupo Bauru (COTTAS \& BARCELOS, 1981; PONÇANO et al., 1982; BRANDT NETO, 1984). Alguns autores propuseram o abandono do termo, por considerarem os depósitos da Formação Itaqueri descontínuos e de pequena expressão geográfica (FREITAS, 1955, 1964;
MEZZALIRA, 1974), enquanto outros expandiram sua área de ocorrência para a região de Franca e Pedregulho (SOARES et al., 1980; BISTRICHI et al., 1981; PONÇANO et al., 1982; MELO \& PONÇANO, 1983).

CABRAL JR. et al. (1992) verificaram que os depósitos atribuídos à Formação Itaqueri, da região de Franca e Pedregulho, encontram-se intercalados entre derrames de rochas básicas da Formação Serra Geral. Esses sedimentos, provisoriamente referidos como Unidade Franca, são interpretados como leques aluviais rudáceos, gerados pelo alçamento da Flexura de Goiânia e biselados pela Superfície Sul-Americana (COIMBRA \& RICCOMINI, 1994).

MORAES REGO (1930) situou as camadas do alto da Serra de Itaqueri no Plioceno, considerando-as, portanto, mais jovens do que o Grupo Bauru, referindo-se a Rubião Júnior, nos arredores de Botucatu, como o local onde esta relação de sobreposição havia sido por ele obser- 
vada. Posteriormente, ALMEIDA \& BARBOSA (1953) julgaram que a situação estratigráfica exposta em Rubião Júnior era a oposta. Em estudos mais recentes, SOARES \& LANDIM (1976) e MELO \& PONÇANO (1983) interpretaram os depósitos de Rubião Júnior como testemunhos da Superfície Sul-Americana, e equivalentes às coberturas das serras de Itaqueri e São Pedro.

Outro aspecto gerador de controvérsias, quanto a posição estratigráfica e idade da Formação Itaqueri, diz respeito à hipótese de não correlação dos sedimentos de cobertura das serras de Itaqueri, Santana e São Carlos, uma vez que eles encontram-se atualmente desnivelados. A aplicação de critérios essencialmente geomorfológicos conduziu à idéia de que se tratavam de depósitos correlativos de diferentes fases de pediplanação (CHRISTOFOLETTI \& QUEIROZ NETO, 1966; PONÇANO, 1981; MELO \& PONÇANO, 1983), em detrimento de desnivelamentos tectônicos, cuja presença é notória na região (BJÖRNBERG, 1965, 1969; FULFARO et al., 1967; PENTEADO, 1968; SOARES, 1974; BRANDT NETO et al., 1981; RICCOMINI et al., 1991; RICCOMINI 1995; LADEIRA \& SANTOS 1996).

No presente trabalho discute-se a posição estratigráfica e o padrão de fraturamento relacionado ao tectonismo deformador da Formação Itaqueri, em sua área-tipo, compreendendo as serras de Itaqueri, São Pedro, Cuscuzeiro e São Carlos, localizadas na porção centro-leste do Estado de São Paulo (FIGURA 1).

\section{CONTEXTO GEOLÓGICO E TECTÔNICO}

RICCOMINI $(1995,1997)$ verificou que os alinhamentos estruturais de direções WNW, NW e NNW, presentes na área geográfica da Bacia do Paraná, no Estado de São Paulo, configuram um padrão em blocos romboidais (FIGURA 1). Tais alinhamentos atuaram na distribuição das unidades sedimentares (AMARAL 1977), dos focos de magmatismo alcalino e dos altos estruturais.

A área de ocorrência da Formação Itaqueri, na região em estudo, é seccionada pelos alinhamentos estruturais do Rio Tietê, de direção NW, do Rio Moji-Guaçu, de direção NNW, e São Carlos - Leme, de direção WNW. O Alinhamento do Rio Moji-Guaçu (COIMBRA et al., 1981) engloba as instruções de Ipanema, Varnhagem e Salto de Pirapora; no seu encontro com o Alinhamento de Cabo Frio (SADOWSKI \& DIAS NETO, 1981; ALMEIDA, 1991) ocorrem os analcimitos de Aparecida do Monte Alto, Piranji, Taiúva e a intrusão de Jaboticabal; e, nas proximidades de seu cruzamento com o Alinhamento Estrutural do Rio Tietê (COIMBRA et al., 1977), é sítio dos altos estruturais de Pitanga, Artemis, Pau d'Alho e Jibóia.

Para RICCOMINI $(1995,1997)$ o traçado da borda leste da Bacia Bauru, a distribuição da Formação Itaqueri e as reentrâncias na atual área de ocorrência das rochas vulcânicas da Formação Serra Geral, são sugestivos da presença de deslocamentos de componentes sinistral e dextral, respectivamente ao longo dos alinhamentos de direção NNW e WNW. O autor relacionou os alinhamentos de direção WNW com estruturas sintéticas (R) e os de direção NNW com estruturas antitéticas (R) de RIEDEL (1929), em um modelo transcorrente com binário dextral de orientação próxima de $\mathrm{E}-\mathrm{W}$ (FIGURA 1). Neste modelo, o Alinhamento do Rio Moji-Guaçu teria componente sinistral, enquanto que os alinhamentos do Rio Tietê e São Carlos - Leme teriam componentes dextrais. Ainda segundo o autor, existem evidências diretas desses deslocamentos, mas há também indicações de movimentações opostas, sugestivas de processos de reativação, e as ocorrências de manifestações alcalinas do Cretáceo Inferior (Ipanema) e Superior (Taiúva, Jaboticabal) são elementos adicionais em favor da existência de atividade tectônica recorrente ao longo desses alinhamentos.

A megaestruturação posterior ao magmatismo Serra Geral é também verificada ao nível das estruturas em escala mesoscópica (falhas e juntas estudadas em afloramentos), tanto em termos geométricos (arranjo espacial) como cinemáticos, relacionadas ao tectonismo deformador pós-sedimentar. Estas estruturas podem ser interpretadas como resultantes de dois regimes transcorrentes (RICCOMINI, 1997).

\section{POSIÇÃO ESTRATIGRÁFICA E IDADE DA FORMAÇÃO ITAQUERI}

A erosão pós-basáltica que preparou o substrato para a deposição da Formação Itaqueri promoveu aplainamento generalizado, removendo as irregularidades deixadas pelas atividades tectônicas precedentes. A formação encontra-se assentada sobre superfície regular, desenvolvida nos basaltos da Formação Serra Geral e localmente nos arenitos eólicos da Formação Botucatu, como nos arredores de Itaqueri da Serra.

A sedimentação da Formação Itaqueri ocorreu sob condições de média a alta energia. Os leques aluviais rudáceos, bem desenvolvidos na Serra de Itaqueri e no flanco leste da Serra de 
São Pedro, passam a ter contribuição mais arenosa no rumo oeste e noroeste, chegando a incorporar intercalações pelíticas nos arredores de Torrinha, onde as condições de sedimentação mais calmas permitiram a preservação de restos vegetais. Dessa maneira, as evidências levam a crer que a sedimentação ocorreu com transporte de leste-sudeste para oeste-noroeste, a julgar pela distribuição das fácies. A contribuição de seixos de folhelhos da Formação Estrada Nova (ALMEIDA \& BARBOSA, 1953) e de rochas magmáticas extrusivas (basaltos) e hipoabissais (diabásios) na sedimentação Itaqueri é sugestiva de que os altos estruturais vizinhos, como o Anticlinal de Pitanga, possivelmente alçados no Maastrichtiano (Neocretáceo), tenham atuado como áreas-fonte destes materiais.

O topo da unidade é também relativamente regular. Existem desníveis entre as cotas de ocorrência nas diferentes serras, provavelmente relacionados ao tectonismo pós-sedimentar, cujas descontinuidades parecem ter exercido marcante influência na conformação atual dos platôs que sustentam a Formação Itaqueri, servindo como caminhos preferenciais ao ataque dos agentes erosivos que vêm causando o recuo da escarpa basáltica e de sua cobertura.

COIMBRA et al. (1981) descreveram os processos de silicificação dos arenitos e conglomerados da Formação Itaqueri, ocorrentes na serra homônima e na de São Carlos, considerando-os de natureza hidrotermal e contemporâneos à sedimentação clástica. Atribuiram relação genética do hidrotermalismo com a manifestação alcalina de Jaboticabal, uma vez que esta e os arenitos silificados encontram-se ao longo do Alinhamento do Rio Moji-Guaçu. Sendo a intrusão de Jaboticabal datada de $54 \mathrm{Ma}$ (e.g. ULBRICH \& GOMES, 1981), a sedimentação da Formação Itaqueri teria igualmente idade ter-

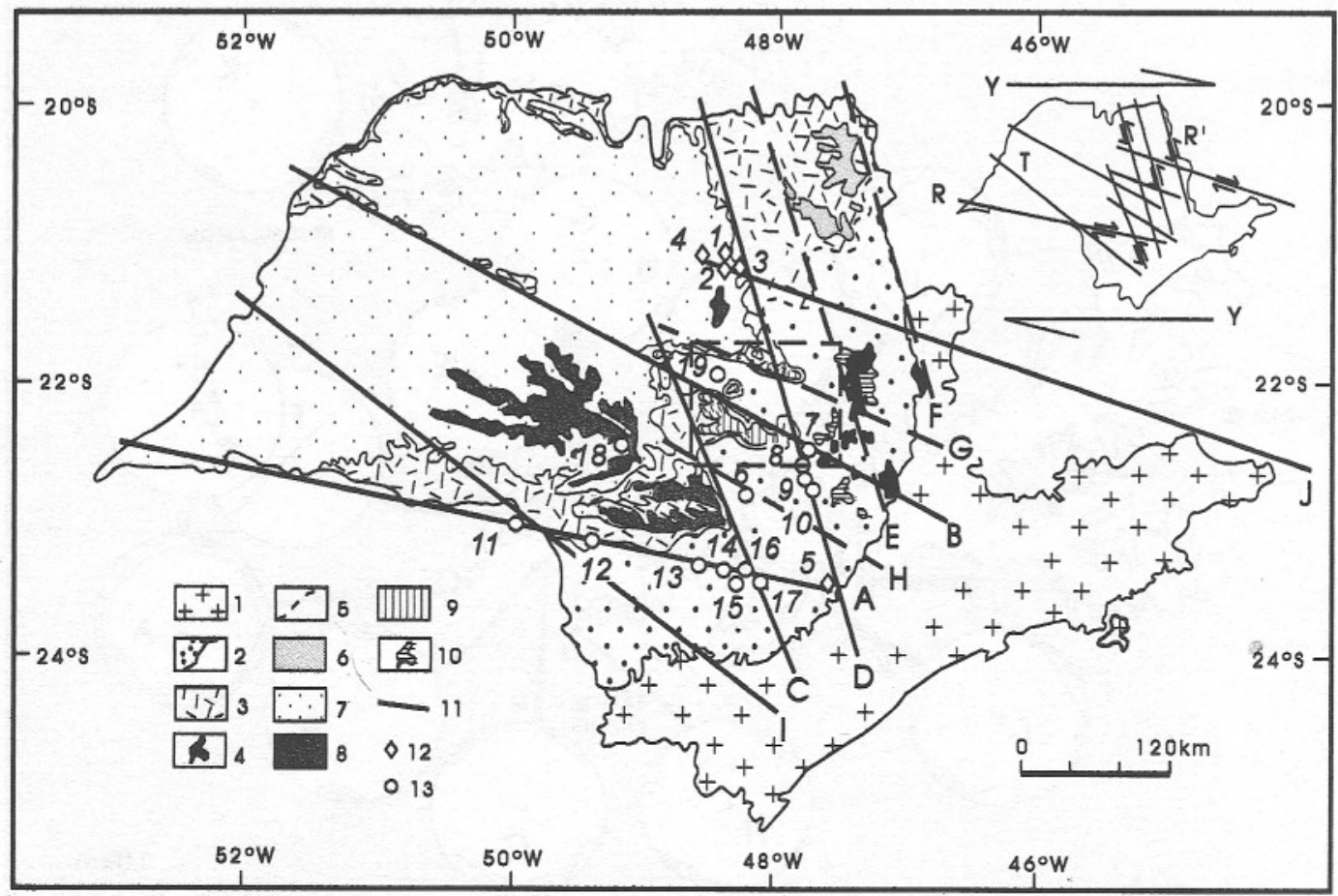

FIGURA 1 - Localização da área-tipo da Formação Itaqueri (retângulo tracejado) na porção centro-leste do Estado de São Paulo (segundo RICCOMINI, 1995, 1997). 1. substrato pré-cambriano, em parte recoberto por sedimentos cenozóicos; 2. terrenos paleozóicos e mesozóicos da Bacia do Paraná, subjacentes aos derrames superiores da Formação Serra Geral; 3. rochas vulcânicas da Formação Serra Geral; 4. sills de diabásio; 5. contato aproximado entre 2 e $3 ; 6$. depósitos rudáceos da região de Franca-Pedregulho; 7. grupos Caiuá e Bauru, não diferenciados; 8. Formação Marília, Grupo Bauru; 9. Formação Itaqueri; 10. Formação Rio Claro e depósitos correlatos; 11. alinhamentos estruturais (A - Rio Paranapanema; B - Tietê; C - Ibitinga - Botucatu; D Rio Moji-Guaçu; E - Ribeirão Preto - Campinas; F - Rifaina - São João da Boa Vista; G - São Carlos - Leme; H - Barra Bonita - Itu; I - Guapiara; J - Cabo Frio); 12. manifestações alcalinas (1 - Taiúva; 2 - Aparecida do Monte Alto; 3 - Jaboticabal; 4 - Piranji; 5 - Ipanema/Araçoiaba da Serra); 13. altos estruturais (6 - Domo de Anhembi-Piapara; 7 - Estrutura de Pitanga; 8 - Domo de Artemis; 9 - Horst de Pau d'Alho; 10 - Domo de Jibóia; 11 - Domo de Jacarezinho; 12 - Domo da Neblina; 13 - Domo de Jacu; 14 - Estrutura Dômica de Carlota Prenz; 15 - Domo de Rio Grande; 16 - Domo de Jacutinga; 17 - Domo de Guarda; 18 - Astroblema de Piratininga; 19 - Domo de Jacaré-Guaçu). Mapa menor: relações dos alinhamentos com fraturas sintéticas (R), antitétiças (R'), de tração (T), em relação a um binário transcorrente dextral de direção E-W (Y). 
ciária inferior (Paleoceno-Eoceno), o que torna provável sua vinculação à Superfície do Japi.

\section{TECTONISMO DEFORMADOR DA FORMAÇÃO ITAQUERI}

A caracterização do tectonismo deformador da Formação Itaqueri e a determinação dos paleocampos de tensões esteve fundamentada na análise estrutural de falhas e juntas, procurandose sempre obter o maior número de dados possível por afloramento. As interpretações referentes à evolução dos campos de esforços, seus mecanismos geradores, e suas relações com a geração-deformação das acumulações sedimentares estiveram alicerçadas na estratigrafia dos depósitos mesozóicos e cenozóicos da região em estudo.

Para o tratamento dos dados estruturais obtidos foram empregados os programas computacionais TRADE (ARTG50), desenvolvido pelo Instituto de Pesquisas Tecnológicas do Estado de São Paulo S.A. (CAMPANHA et al., 1996), e QUICKPLOT, desenvolvido por VAN EVERDINGEN \& VAN GOOL (1990). Todos os diagramas estruturais apresentados correspondem à rede de Schmidt-Lambert, tendo como referência a semi-esfera inferior.

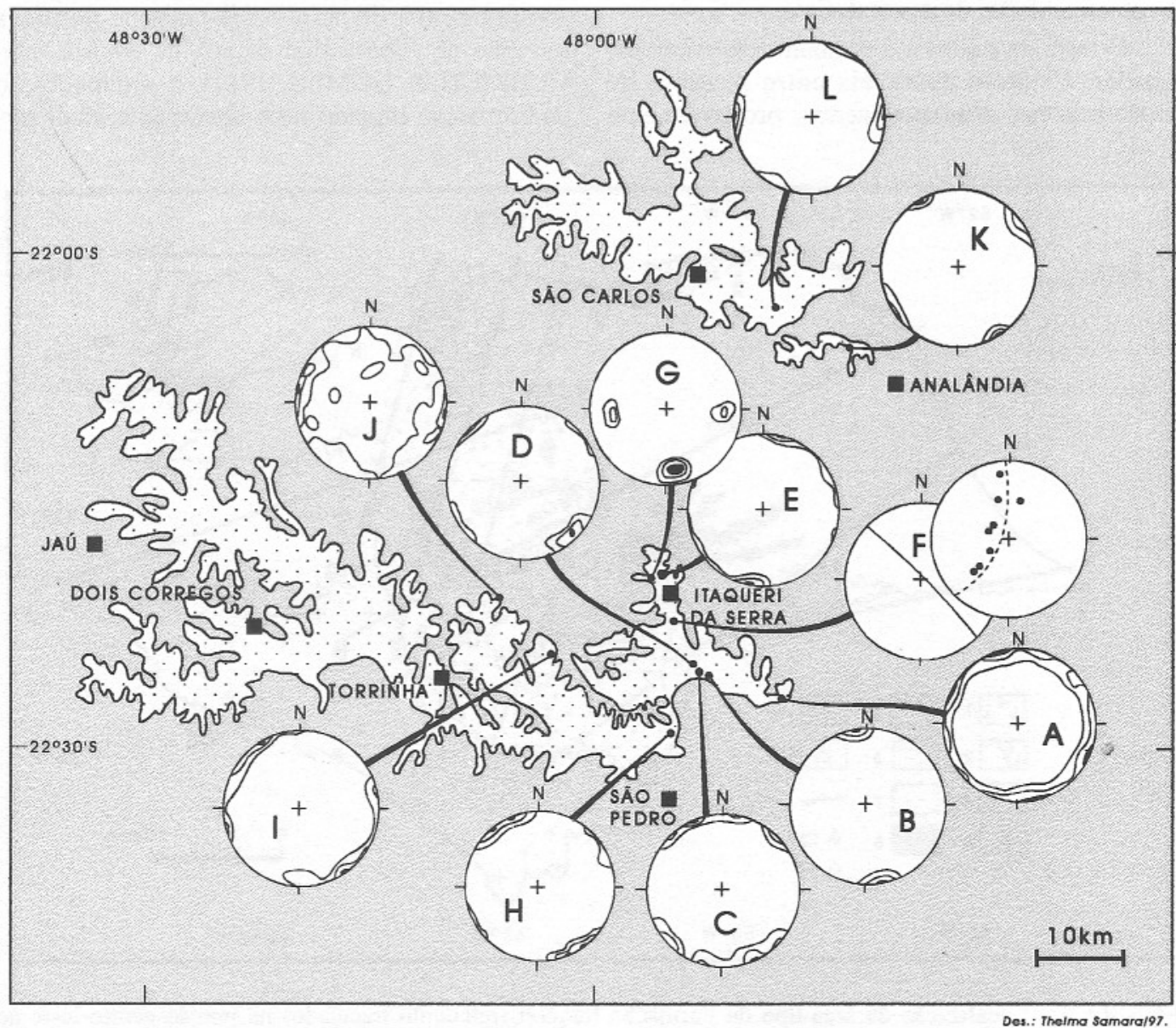

FIGURA 2 - Estruturas da Formação Itaqueri (área pontilhada) nas serras de Itaqueri, São Pedro, Cuscuzeiro e São Carlos. Locais de estudos, números de dados, valores das curvas de isofreqüência a partir do centro dos diagramas: A. coordenadas UTM 214,0 km E, 7.515,2 km N, falhas e fraturas, 102 dados, curvas de 1, 4 e 7\%; B. $203,3 \mathrm{~km} \mathrm{E,} \mathrm{7.517,2} \mathrm{km} \mathrm{N,} \mathrm{fraturas,} 51$ dados, curvas de 7, 14 e 21\%; C. 203,0 km E, 7.517,5 km N, fraturas, 41 dados, curvas de 3, 8 e 14\%; D. 203,0 km E, 7.517,7 km N, falhas e fraturas, 34 dados, curvas de 6, 12 e $18 \%$; E. 198,7 km E, 7.528,5 km N, fraturas, 45 dados, curvas de 5,10 e $15 \%$; F. 200,3 km E, 7.254,3 $\mathrm{km} \mathrm{N}$, falha (1 dado, círculo máximo) e pólos de superfície So dobrada ( 8 dados, com círculo mínimo tracejado); G. 198,2 km E, 7.528,2 km N, fraturas, 22 dados, curvas de 5, 10 e 15\%; H. 200,6 km E, 7.510,3 $\mathrm{km} \mathrm{N}$, falhas, 51 dados, curvas de 4,9 e $14 \%$; I. $804,6 \mathrm{~km} \mathrm{E}, 7.519,4 \mathrm{~km} \mathrm{~N}$, fraturas no basalto, 45 dados, curvas de 3, 7 e 11\%; J. 797,8 km E, 7.526,0 km N, fraturas no basalto, 50 dados, curvas de 1, 5 e $9 \% ; \mathrm{K}$. $220,2 \mathrm{~km} \mathrm{E}, 7.555,0 \mathrm{~km} \mathrm{~N}$, fraturas, 54 dados, curvas de 5, 10 e 15\%; L. 211,5 km E, 7.559,5 km N, falhas e fraturas, 67 dados, curvas de 1, 6 e 11\% (locais A a J nas serras de Itaqueri e São Pedro, K na Serra do Cuscuzeiro e L na Serra de São Carlos). 
Na FIGURA 2 estão assinalados os locais onde foram obtidos dados estruturais para a Formação Itaqueri em sua área-tipo. Para todas as localidades estudadas são fornecidas coordenadas UTM, obtidas com auxílio de GPS (Ensigne, Trimble/Navigation). Os dados estão concentrados na porção leste da área, nas serras de São Pedro, Itaqueri, Cuscuzeiro e São Carlos, em função da própria distribuição dos sedimentos tectonicamente perturbados. Compreendem estruturas pós-sedimentares, principalmente falhas de caráter transcorrente, localizadamente com dobras en échelon associadas, e também fraturas, que em grande parte correspondem a falhas, onde não se pode detectar a movimentação relativa entre os blocos, em função das características litológicas dos sedimentos.

As descontinuidades observadas nas rochas sedimentares são subverticais, apresentam espaçamento variado, predominando o decimétrico, e não são preenchidas. Seu caráter tectônico e pós-sedimentar é atestado por afetarem rochas inteiramente litificadas e pela persistência em área dos padrões reconhecidos (RICCOMINI, 1997). As direções principais são ENE e WNW, ocorrendo secundariamente NNW, NE e NNE. Possuem arranjo geométrico variado, compreendendo famílias de fraturas conjugadas das seguintes classes: a) fraturas de extensão ( $v . g$. POLLARD \& AYDIN, 1994) nos locais B e J; b) fraturas híbridas (DUNNE \& HANCOCK, 1994), como no local C, por vezes incluindo cross-joints (HANCOCK \& ENGELDER, 1989), como em A, E e H; c) fraturas de cisalhamento (DUNNE \& HANCOCK, 1994), nos locais I e L; e d) fraturas ortogonais (v.g. CAPUTO, 1995), nos locais D e G. Em todos os casos as fraturas comportariam um eixo de tensão principal máxima, $\sigma 1$, no quadrante NE.

Poucas são as indicações de sentido de deslocamento: nos locais B e F (FIG. 2), falhas de direção N45W apresentam rejeito de componente transcorrente dextral; no local $\mathrm{H}$ ocorrem falhas de direção NNW com componente sinistral; em L, falhas de direção NNE apresentam deslocamento transcorrente sinistral de componente normal (RICCOMINI, 1995). Tais indicações, aliadas à disposição geral das estruturas, seriam compatíveis com um eixo de tensão principal máxima, $\sigma 1$, de orientação NW, horizontal, eixo de tensão principal mínima, $\sigma 3, \mathrm{NE}$, horizontal, e eixo intermediário, $\sigma 2$, vertical, relacionados a um binário transcorrente dextral de direção geral WNW a E-W.

Os sedimentos falhados das serras de Itaqueri e São Pedro encontram-se nas proximidades da junção dos alinhamentos do Rio Tietê e do Rio Moji-Guaçu, e os das serras de São
Carlos e Cuscuzeiro sobre o Alinhamento São Carlos-Leme. Os deslocamentos verificados permitem supor que as deformações estejam relacionadas com movimentações ao longo dessas feições maiores. As principais direções estruturais obtidas são coincidentes com a conformação atual dos platôs que sustentam os depósitos da Formação Itaqueri.

No quadro evolutivo estabelecido por RICCOMINI (1995) para a porção centro-oriental do Estado de São Paulo e áreas vizinhas, o tectonismo deformador da Formação Itaqueri na região estudada contemplaria duas idades alternativas, paleogênica ou quaternária. Tendo em vista o controle das estruturas sobre a morfologia, especialmente na conformação dos platôs que sustentam a Formação Itaqueri e no padrão de drenagem, atribui-se, em caráter preliminar, idade quaternária (pleistocênica superior a holocênica) para as falhas estudadas.

\section{CONCLUSÕES}

Os levantamentos conduzidos na área-tipo da Formação Itaqueri, compreendendo as serras de Itaqueri, São Pedro, São Carlos e Cuscuzeiro, situadas na porção centro-leste do Estado de São Paulo, permitiram verificar que a gênese da unidade possui relação com a evolução da Superfície de Aplainamento Japi. A silicificação penecontemporânea à deposição dos arenitos, associada ao hidrotermalismo resultante da colocação de corpos de rochas alcalinas ao longo do Alinhamento Moji-Guaçu, leva à atribuição de idade paleocênica-eocênica para a Formação Itaqueri.

As estruturas rúpteis geradas durante o tectonismo deformador, principalmente falhas e juntas, estão relacionadas com movimentações ao longo dos alinhamentos estruturais do Tietê, São Carlos - Leme e Moji-Guaçu. As falhas possuem um eixo de tensão principal máxima, $\sigma 1$, de orientação NW, horizontal, eixo de tensão principal mínima, $\sigma 3, \mathrm{NE}$, horizontal, e eixo intermediário, $\sigma 2$, vertical, compatíveis com um binário transcorrente dextral de direção geral WNW a E-W, com provável atividade neotectônica, durante o Quaternário.

\section{AGRADECIMENTOS}

$\mathrm{O}$ autor externa seus agradecimentos ao Dr. Thomas R. Fairchild pela revisão do abstract e Sra. Thelma Samara pela confecção das figuras. 


\section{REFERÊNCIAS BIBLIOGRÁFICAS}

AB'SÁBER, A.N.1969. Formações quaternárias em áreas de reverso de cuestas em São Paulo: Geomorfologia, 16:1-11.

ALMEIDA, F.F.M. 1991. O Alinhamento Magmático de Cabo Frio. In: SIMPÓSIO DE GEOLOGIA DO SUDESTE, 2., São Paulo, Atas. São Paulo: SBG/SP, p.423428.

ALMEIDA, F.F.M. \& BARBOSA, O. 1953. Geologia das quadrículas de Piracicaba e Rio Claro, Estado de São Paulo. Bol. $D N P M / D G M, 143: 96 \mathrm{p}$.

AMARAL, G. 1977. Padrões fotogeológicos dos litofácies da Formação Bauru no Estado de São Paulo, como observados em imagens LANDSAT. In: SIMPÓSIO DE GEOLOGIA REGIONAL, 1., São Paulo. Atas. São Paulo: SBG, p. 439-499.

BARCELOS, J.H., SOUZA FILHO, E.E., FULFARO, V.J., LANDIM, P.M.B., COTTAS, L.R., WU, F.T. \& GODOY, A.M.1983. A Formação Itaqueri: um exemplo de tectofácies. In: SIMPÓSIO REGIONAL DE GEOLOGIA, 4., São Paulo. Atas. São Paulo: SBG, p.245-252.

BISTRICHI, C.A, CARNEIRO, C.D.R., DANTAS, A.S.L., PONÇANO, W.L., CAMPANHA, G.A.C., NAGATA, N., ALMEIDA, M.A., STEIN, D.P., MELO, M.S. \& CREMONINI, O.A. 1981. Mapa geológico do Estado de São Paulo. Escala I:500.000. São Paulo: SICCT, v.1, 126p.

BJÖRNBERG, A.J.S. 1965. Sedimentos póscretácicos do leste do Estado de São Paulo. São Carlos, 133p. (Tese de livredocência apresentada à Escola de Engenharia de São Carlos da Universidade de São Paulo)

BJÖRNBERG, A.J.S. 1969. Contribuição ao estudo do Cenozóico paulista: tectônica e sedimentologia. São Carlos, 128p. (Tese para o provimento do cargo de Professor apresentada à Escola de Engenharia de São Carlos da Universidade de São Paulo)

BRANDT NETO, M. 1984. O Grupo Bauru na região centro-norte do Estado de São Paulo. São Paulo, 2v. (Tese de doutorado apresentada ao Instituto de Geociências da Universidade de São Paulo)

BRANDT NETO, M., COIMBRA, A.M., BARELLI, N. \& SPILLER, L.R. 1981.
Sedimentos da Serra de Itaqueri. In: A FORMAÇÃO BAURU NO ESTADO DE SÃO PAULO E REGIÕES ADJACENTES, São Paulo. Coletânea de trabalhos e debates. São Paulo: SBG, p.63-80.

CABRAL JR., M., MOTTA, J.F.M., TANNO, L.C., HELLMEISTER JR., Z. \& COIMBRA, A.M. 1992. Revisão estratigráfica do nordeste do Estado de São Paulo. In: SIMPÓSIO SOBRE AS BACIAS CRETÁCICAS BRASILEIRAS, 2., Rio Claro. Resumos Expandidos. Rio Claro: UNESP, p.134-136.

CAMPANHA, G.A.C., CARNEIRO, C.D.R., PEREIRA JR., G.G., FURUMOTO, S., HASUI, Y. \& NAGATA, N. 1996. Uso do programa TRADE para determinação de direções principais de esforços pelos métodos Arthaud e Angelier. In: CARNEIRO, C.D.R. coord. Projeção estereográfica para análise de estruturas. São Paulo: UNICAMP/CPRM/IPT, p.115120.

CAPUTO, R. 1995. Evolution of orthogonal sets of coeval extension joints. Terra Nova, 7:479-490.

CHRISTOFOLETTI, A. \& QUEIROZ NETO, J.P. 1966. Os sedimentos da Serra de Santana, SP. Bol. Paran. Geogr., 1820:231-245.

COIMBRA, A.M. \& RICCOMINI, C. 1994. Geologia das ocorrências minerais não-metálicas de origem sedimentar do Estado de São Paulo? In: WORKSHOP RECURSOS MINERAIS NÃO-METÁLICOS PARA O ESTADO DE SÃO PAULO, São Paulo. Resumos Expandidos. São Paulo: SBG, p.11-21.

COIMBRA, A.M., BRANDT NETO, M.\& PETRI, S. 1977. O alinhamento estrutural do Tietê. In: SIMPÓSIO REGIONAL DE GEOLOGIA, 1., São Paulo. Atas. São Paulo: SBG, p.145-152.

COIMBRA, A.M., BRANDT NETO, M. \& COUTINHO, J.M.V. 1981. Silicificação dos arenitos da Formação Bauru no Estado de São Paulo. In: A FORMAÇÃO BAURU NO ESTADO DE SÃO PAULO E REGIÕES ADJACENTES, São Paulo. Coletânea de trabalhos e debates. São Paulo: SBG, p.103-115. 
COTTAS, L.R. \& BARCELOS, J.H. 1981. Novas considerações sobre a região de Itaqueri da Serra. In: SIMPÓSIO REGIONAL DE GEOLOGIA, 3., Curitiba. Atas. Curitiba: SBG, v.2, p.7076.

DUNNE, W.M. \& HANCOCK, P.L. 1994. Palaeostress analysis of small-scale brittle structures. In: HANCOCK, P.L., editor, Continental Deformation. Oxford, Pergamon, p.101-120.

FREITAS, R.O. 1955. Sedimentação, estratigrafia e tectônica da Série Bauru. Bol. Fac. Fil. Ci. e Letras, 194:1-185.

FREITAS, R.O. 1964. Grupo Bauru. Bol. IGG, 41:126-147.

FULFARO, V.J., LANDIM, P.M.B. \& ELLERT, N. 1967. A tectônica das serras de Santana e São Pedro (Serra Geral). In:CONGRESSO BRASILEIRO DE GEOLOGIA, 21., Curitiba, Anais... Curitiba: SBG, p.198-205.

HANCOCK, P.L. \& ENGELDER, T. 1989. Neotectonic joints. Geol. Soc. Am. Bull., 101:1197-1208.

HASUI, Y. \& SADOWSKI, G.R. 1972. Membro Itaqueri e Facies Ponte Alta. Ciência e Cultura, 24:138-139.

LADEIRA, F.S.B. \& SANTOS, M. 1996. Ferricrete terciária falhada na Serra de São Pedro (SP): indicação de movimentação neotectônica. Geociências, 15:445-453.

MELO, M.S. \& PONÇANO, W.L. 1983. Gênese, distribuição e estratigrafia dos depósitos cenozóicos no Estado de São Paulo. São Paulo, Instituto de Pesquisas Tecnológicas do Estado de São Paulo S.A., 74p. (Monografia n. 9)

MEZZALIRA, S. 1974. Contribuição ao conhecimento da estratigrafia e paleontologia do Arenito Bauru. Bol. $I G G$, 51:1-163.

MORAES REGO, L.F. 1930. A geologia do petróleo no Estado de São Paulo. Bol. Serv. Geol. Min., DNPM, 46:1-110.

PENTEADO, M.M. 1968. Implicações tectônicas na gênese das cuestas da Bacia de Rio Claro (SP). Notícia Geomorfológica, 8:19-41.

POLLARD, D.D. \& AYDIN, A. 1988. Progress in understanding jointing over the past century. Bull. Geol. Soc. Am., 100:11811204.
PONÇANO, W.L. 1981. As coberturas cenozóicas. In: BISTRICHI, C.A, CARNEIRO, C.D.R, DANTAS, A.S.L., PONÇANO, W.L., CAMPANHA, G.A.C., NAGATA, N., ALMEIDA, M.A., STEIN, D.P., MELO, M.S. \& CREMONINI, O.A. Mapa geológico do Estado de São Paulo. Escala 1:500.000. São Paulo, SICCT, v.1, p.82-126.

PONÇANO, W.L., STEIN, D.P., ALMEIDA, F.F., ALMEIDA, M.A. \& MELO, M.S. 1982. A Formação Itaqueri e depósitos correlatos no Estado de São Paulo. In: CONGRESSO BRASILEIRO DE GEOLOGIA, 32., Salvador. Anais... Salvador: SBG, v.4, p.1339-1350.

RICCOMINI, C. 1995. Tectonismo gerador e deformador dos depósitos sedimentares pós-gondvânicos da porção centrooriental do Estado de São Paulo e áreas vizinhas. São Paulo, 100p. (Tese de livredocência apresentada ao Instituto de Geociências da Universidade de São Paulo)

RICCOMINI, C. 1997. Arcabouço estrutural e aspectos do tectonismo gerador e deformador da Bacia Bauru no Estado de São Paulo. Rev. Bras. Geoc., 27:153-162.

RICCOMINI, C., POHL, L.L., FELISBINO JR., S.E., FAMBRINI, G.L. \& SANT'ANNA, L.G. 1991. Tectônica transcorrente na Bacia do Paraná: o exemplo da Zona de Cisalhamento de Paraisolândia, SP. In: SIMPÓSIO DE GEOLOGIA DO SUDESTE, 2., São Paulo. Atas. São Paulo: SBG-SP/RJ, p.181-182.

RIEDEL, W. 1929. Zur Mechanik, geologischer Brucherscheinungen. Ein, Beitrag zum Problem der "Fiederspalten". Zentralbl. $f$. Mineral., Geol., u. Paleont., 1929B:354368.

SADOWSKI, G.R. \& DIAS-NETO, C.M. 1981. O lineamento sismo-tectônico de Cabo Frio. Rev. Bras. Geoc., 11:209-212.

SOARES, P.C. 1974. Elementos estruturais da parte nordeste da Bacia do Paraná: classificação e gênese. In: CONGRESSO BRASILEIRO DE GEOLOGIA, 28., Porto Alegre. Anais... Porto Alegre: SBG, v.4, p.107-121.

SOARES, P.C. \& LANDIM, P.M.B. 1976. Depósitos cenozóicos na região centro-sul do Brasil. Notícia Geomorfológica, 16:17-39. 
SOARES, P.C., LANDIM, P.M.B., FULFARO, V.J. \& SOBREIRO NETO, A.F. 1980. Ensaio de caracterização do Cretáceo no Estado de São Paulo. Rev. Bras. Geoc., 10:177-185.

ULBRICH, H.H.G.J. \& GOMES, C.B. 1981. Alkaline rocks from continental Brazil. Earth Science Reviews, 17:135-154.
VAN EVERDINGEN, D. \& VAN GOOL, J. 1990. QuickPlot, plotting program for orientation data. Newfoundland, Department of Earth Sciences, Memorial University of Newfoundland. 